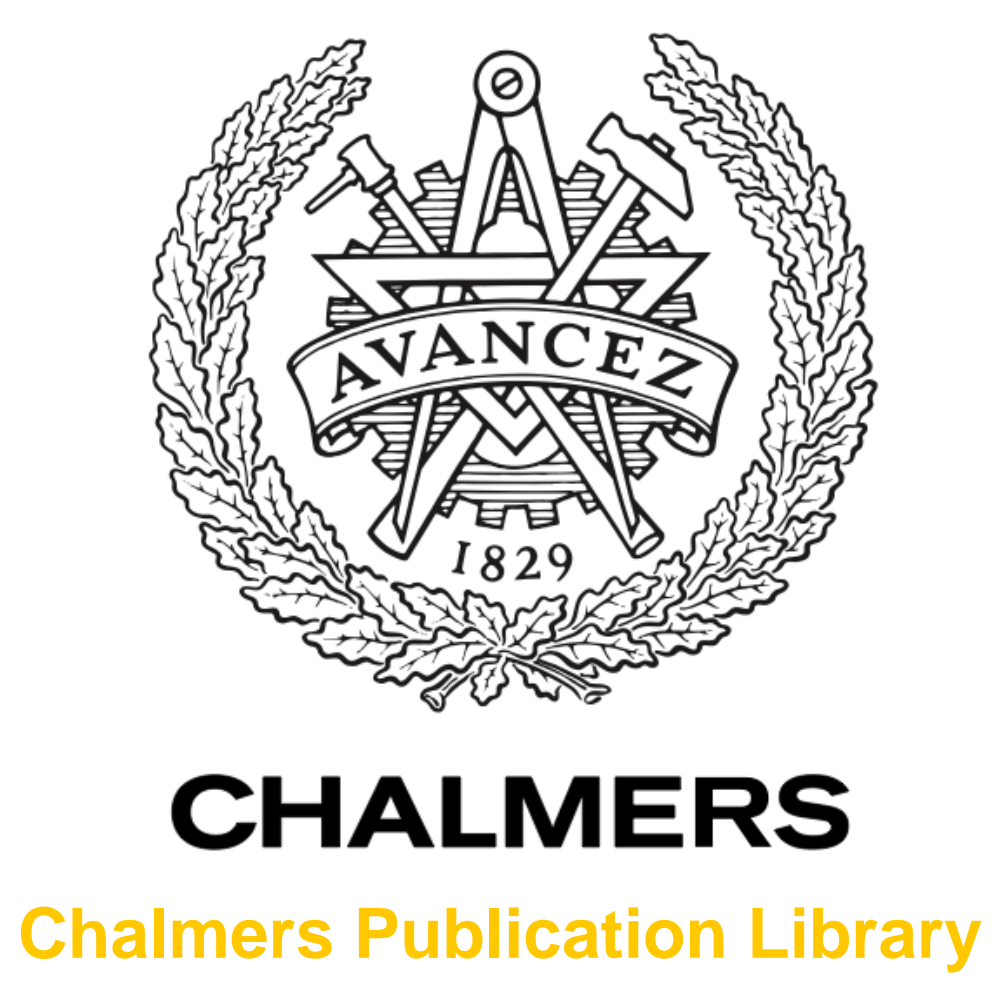

\title{
Detection of Combustion Properties in a Diesel Engine using Block Mounted Accelerometers
}

This document has been downloaded from Chalmers Publication Library $(\mathrm{CPL})$. It is the author's version of a work that was accepted for publication in:

\section{Preprints of the 19th World Congress The International Federation of Automatic Control Cape Town, South Africa. August 24-29,}

Citation for the published paper:

Andersson, I. ; McKelvey, T. ; Larsson, M. (2014) "Detection of Combustion Properties in a Diesel Engine using Block Mounted Accelerometers". Preprints of the 19th World Congress The International Federation of Automatic Control Cape Town, South Africa. August 24-29, pp. 11866-11871.

Downloaded from: http://publications.lib.chalmers.se/publication/202758

Notice: Changes introduced as a result of publishing processes such as copy-editing and formatting may not be reflected in this document. For a definitive version of this work, please refer to the published source. Please note that access to the published version might require a subscription. 


\title{
Detection of Combustion Properties in a Diesel Engine using Block Mounted Accelerometers
}

\author{
Ingemar Andersson* Tomas McKelvey* Martin Larsson ** \\ * Department of Signals and Systems \\ Chalmers University of Technology \\ SE-412 96 Göteborg, Sweden \\ $\{$ ia,mckelvey\}@chalmers.se \\ ** Department of Applied Mechanics \\ Chalmers University of Technology \\ SE-412 96 Göteborg, Sweden
}

\begin{abstract}
Engine block mounted accelerometers was used for estimating combustion phasing parameters for a heavy duty diesel engine. Several sensor locations were evaluated for its sensitivity to combustion related vibrations and mechanical noise.

One sensor-cylinder combination was selected for the evaluation of a simple algorithm to detect $10 \%$ and $50 \%$ burned mass fraction. The algorithm uses the accumulated accelerometer vibration energy as a base for extracting the $10 \%$ and $50 \%$ points respectively.

The results show that the angular positions for $10 \%$ and $50 \%$ burned mass fraction can be estimated with precisions of 1.5 and $3 \mathrm{CAD}$ respectively. It is also concluded that the early part of the accelerometer signal has a significant influence from a mechanical noise source related to the start of injection.
\end{abstract}

Keywords: Diesel engines, Engine control, Feedback systems, Signal processing, Accelerometer, Structure borne sound, Vibration, Knock sensor

\section{INTRODUCTION}

Combustion monitoring for control and diagnostics of diesel engines is gaining attention in the automotive and utility engine industry, and among research groups worldwide. The goal is to reduce calibration efforts for the increasingly more complex control systems governing the engine operations, and find means for detecting faulty and/or aging components. Fuel quality detection and adaptation becomes possible, and more advanced combustion concepts, as partially or fully pre-mixed diesel (pHCCI and HCCI), are made available through combustion feedback (Schnorbus et al., 2008). It may even be possible to relax the tolerances on component manufacturing if the combustion monitoring system allows for individual calibration on-line.

Many combustion parameters are of interest, e.g. angular location of start of combustion (SOC), peak pressure, maximum heat release and $50 \%$ heat release $\left(\theta_{Q 50}\right)$. They all have one common denominator; they occur near the top dead center (TDC) of the piston movement.

Several sensors methodologies are currently explored for combustion monitoring. Cylinder pressure sensors are tractable for their direct measurement of a combustion property that relatively easy translates into any desired combustion performance parameter (Powell, 1993), but the trade-off between cost, durability and accuracy for these sensors opens the field for alternatives. Ion sensing has shown the capacity to detect the start of combustion in diesel engines(Glavmo et al., 1999). Angular speed measurements have been used for a long time for misfire detection, and lately combustion torque and phasing estimation (Aono et al., 2013; Ponti et al., 2013). Crankshaft torque sensors have shown good results in detecting individual cylinder performance (Andersson et al., 2012). Angular speed and crankshaft torque sensors are known to be more robust and less expensive than pressure sensors, but they suffer from one important limitation; they cannot measure a direct effect of the combustion at TDC.

Block mounted accelerometers, or knock sensors, are relatively cheap and durable, and they are sensitive to combustion events at the TDC. On the other hand, they are also sensitive to mechanical noise from e.g. valve trains which needs to be considered in the signal processing. Recent efforts are developing the knowledge in how its signal relates to the combustion. Polonowski et al. (2007) and Chiavola et al. (2010) analyzed the coherence for different frequency bands between the accelerometer signal and the pressure based heat release in a diesel engine, and Villarino and Boehme (2005) have developed methods for reconstructing cylinder pressure and used it for misfire detection and peak pressure position estimation.

In this work, a more simple approach is evaluated. The vibration signal energy is analyzed and compared to combustion properties. 


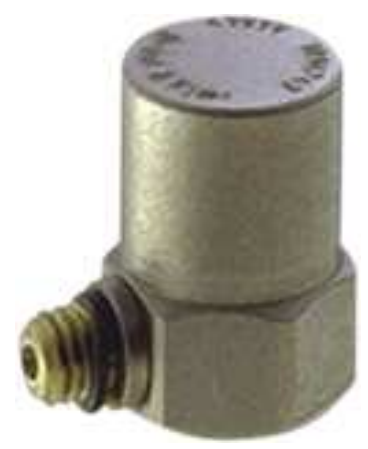

Fig. 1. Brüel \& Kjær piezoelectric accelerometer, model 4393. Copyright (CBrüel \& Kjær

\begin{tabular}{|l|l|}
\hline Displaced volume & $12780 \mathrm{~cm}^{3}$ \\
Bore & $131 \mathrm{~mm}$ \\
Stroke & $158 \mathrm{~mm}$ \\
Compression ratio & $16.2: 1$ \\
Ignition order & 153626 \\
\hline
\end{tabular}

Table 1. Data for the 6-cylinder diesel engine.

\section{EXPERIMENTS}

This study is based on block mounted accelerometer and in-cylinder pressure data collected from a 12.8 liter 6cylinder Volvo Trucks heavy duty diesel engine, see Table 1.

The engine is equipped with Delphi E3 unit injectors, where the injection event is controlled by two valves, the spill control valve (SCV) and the needle control valve (NCV). The SCV controls the build-up of the injection pressure and the NCV controls the start of injection (SOI). The SCV and the NCV are electrically operated and the start of injection position coincides with the NCV opening position. The injection is finished by opening the SCV and closing the NCV. The needle closes when the fuel pressure in the injector has fallen below the level that overcomes the needle spring and the combustion pressure. By altering the SCV and NCV positions it is possible to create a range of combustion scenarios, both in timing and burn rate.

The accelerometers used are Brüel \& Kjær 4393 uni-axle sensors (see Figure 1), with a frequency range of 0.1-16500 $\mathrm{Hz}$ (10\% limit). Six sensors were positioned on a wide range of locations on the engine block. A Brüel \& Kjær charge conditioning amplifier 2635 was used to amplify the accelerometer signals. The cylinder pressure sensors are water-cooled Kistler 7061B connected to a Kistler 5044 charge amplifier.

The engine position was monitored using a 0.1 CAD resolution crank angle encoder on the free end of the crank shaft. The data was collected using the OSIRIS data acquisition system. The engine was run at a range of operating points between $1200-1800 \mathrm{rpm}, 0-100 \%$ load and injection timing varying from -10 to +9 CAD ATDC, see Table 2. A single injection is used for all operating points. The ignition delay is defined as the time between the SOI and 10\% heat released and the Q50 is the angular position of $50 \%$ heat released. The average value of these two entities are also presented for each operating point in Table 2.

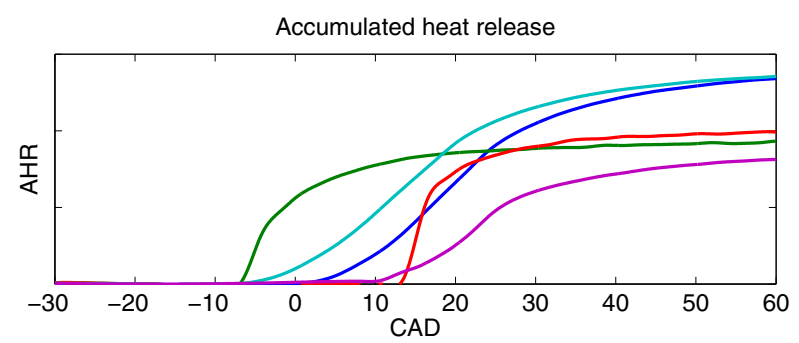

Cylinder pressure

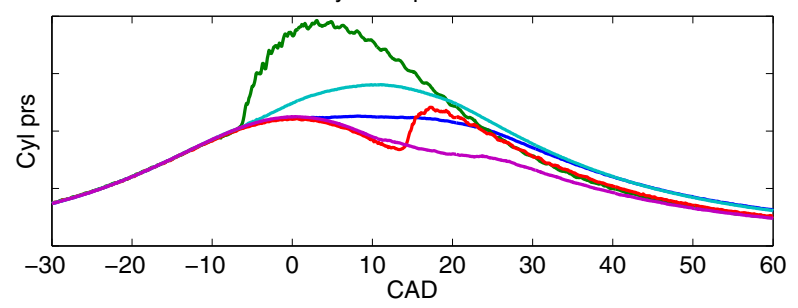

Fig. 2. Examples of the different burn characteristics in the data set.
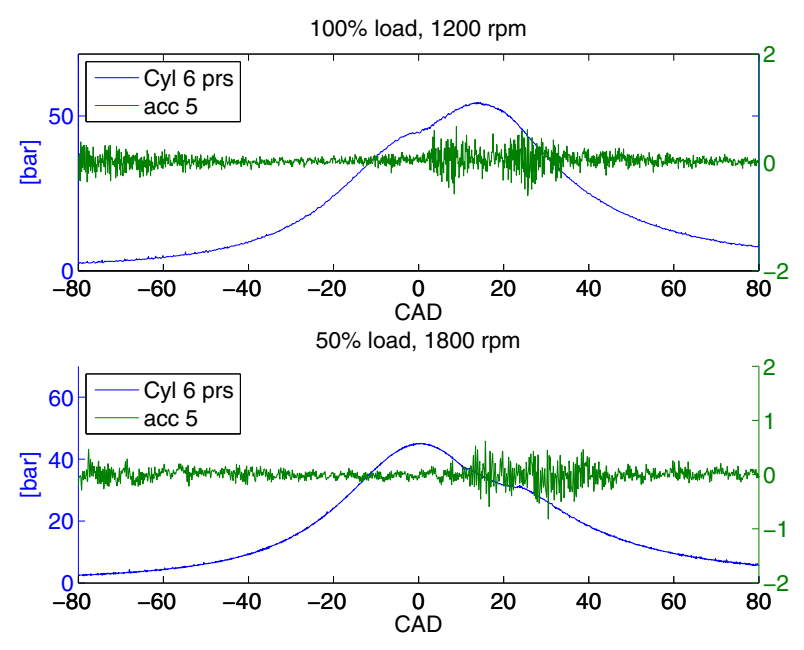

Fig. 3. The cylinder pressure for cylinder 6 and accelerometer signal from position 5 on the engine block. Two different speeds and loads.

Figure 2 shows examples of the burn characteristics in the data set. There are fast and slow burn rates positioned both early and late. Figure 3 shows examples of the accelerometer signal for two different engine speeds and loads. The accelerometer signal is clearly positioned and correlated to the combustion event. In the beginning of the accelerometer signal (around -80 CAD) vibrations originating from the combustion event in cylinder 3 can be seen.

\section{SENSOR POSITIONING AND SIGNAL QUALITY}

Six sensors were mounted on the engine block through the experiments with positions 1-6, see Figure 4. The first task is to select an accelerometer-cylinder pressure combination that is suited for this investigation, meaning that the accelerometer signal shows as much combustion response as possible.

The raw accelerometer signal $u(t)$ is sampled at crank angle positions $\theta_{n}$ with a resolution of $0.1 \mathrm{CAD}$, into a data 


\begin{tabular}{|c|c|c|c|c|c|}
\hline$\#$ & Speed (rpm) & Load (\%) & SOI (CAD ATDC) & Ign delay (CAD) & $\theta_{Q 50}$ (CAD ATDC) \\
\hline 1 & 1200 & 100 & 0 & 6 & 17 \\
2 & 1200 & 100 & 1 & 7 & 21 \\
3 & 1200 & 75 & 5 & 5 & 19 \\
4 & 1200 & 75 & 6 & 6 & 22 \\
5 & 1200 & 50 & -5 & 4 & 6 \\
6 & 1200 & 50 & 7 & 6 & -1 \\
7 & 1200 & 25 & -10 & 5 & 17 \\
8 & 1200 & 25 & 8 & 6 & 11 \\
9 & 1500 & 100 & -8 & 7 & 5 \\
10 & 1500 & 100 & -7 & 5 & 20 \\
11 & 1500 & 50 & -9 & 5 & 7 \\
12 & 1500 & 50 & 7 & 5 & 25 \\
13 & 1800 & 50 & -8 & 6 & 15 \\
14 & 1800 & 50 & 9 & 7 & 10 \\
15 & 1800 & 100 & -5 & 7 & 5 \\
16 & 1800 & 100 & -10 & 5 & \\
\hline
\end{tabular}

Table 2. The data set. Each operating point contains 100 cycles of data.

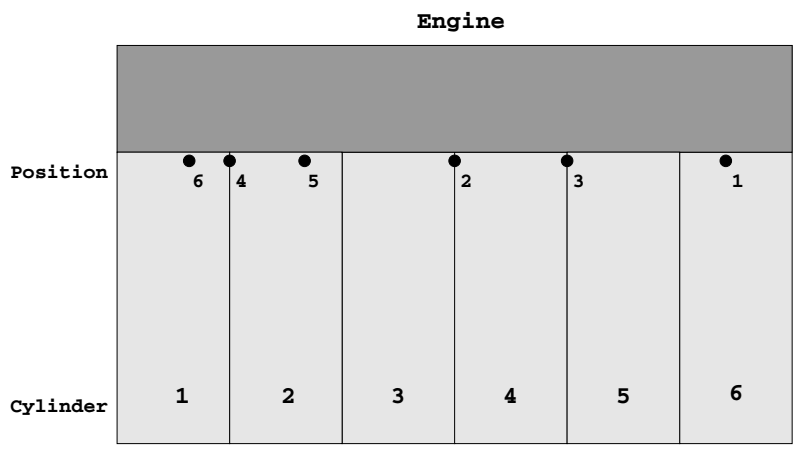

Fig. 4. Positions of the accelerometers on the engine.

sequence $u\left(\theta_{n}\right)$. The sampled signal $u\left(\theta_{n}\right)$ is windowed using a rectangular window $W_{R}(n)$ of length $L$, which is selected to cover the combustion:

$$
\begin{aligned}
& u_{w}\left(\theta_{n}\right)=u\left(\theta_{n}\right) W_{R}(n) \\
& W_{R}(n)= \begin{cases}1 & 0 \leq n<L-1 \\
0 & \text { otherwise }\end{cases}
\end{aligned}
$$

The reference point $(n=0)$ is selected so that $\theta_{0}$ captures the start of injection. The total signal energy $E_{t o t}$ within the window $W_{R}$ is calculated as

$$
E_{t o t}=\sum_{k=0}^{L-1} u_{w}^{2}\left(\theta_{k}\right)
$$

Two operating events are considered for each sensor;

(1) combustion at low load, and

(2) motoring.

The ratio between the two energy levels give a signal-tonoise ratio (SNR) which is used to determine which sensor location is best for detecting the combustion events in a certain cylinder.

$$
\mathrm{SNR}=\frac{E_{\text {low load }}}{E_{\text {motored }}}
$$

Table 3 shows the estimated SNR. There are several good sensor-cylinder pair candidates and clearly the position of the sensor is important. Sensors positioned far away from the measured cylinder seem to perform better in measuring the combustion effect than the ones mounted close, for this engine. Based on this analysis, sensor 5 was used in this work for the estimation of combustion properties

\begin{tabular}{|c|cccccc|}
\hline Sensor & \multicolumn{7}{|c|}{ Cylinder } \\
position & 1 & 2 & 3 & 4 & 5 & 6 \\
\hline 1 & 81 & 36 & 7.6 & 3.1 & 1.1 & 1.4 \\
2 & 2.1 & 2.4 & 1.6 & 5.1 & 5.2 & 6.2 \\
3 & 11 & 26 & 6 & 1.3 & 1.4 & 2.4 \\
4 & 0.6 & 1.2 & 2.6 & 17 & 53 & 150 \\
5 & 0.66 & 1 & 1.8 & 10 & 24 & 24 \\
6 & 0.61 & 1.4 & 2.6 & 6.9 & 31 & 71 \\
\hline
\end{tabular}

Table 3. Results from analyzing the SNR for the different sensor locations.

in cylinder 6 , since apart from having a good SNR, the signal showed less noisy components near the TDC in the motoring case.

The theoretical background is that the combustion event initiates a vibration that travels through the engine block to the accelerometer. The accelerometer signal is therefore delayed compared to cylinder pressure measurements.

The delay is calculated from the speed of structure borne sound and estimates of the distance between the sensor position and the cylinder in question. The speed of sound in iron is $5180 \mathrm{~m} / \mathrm{s}$ (Nordling and Österman, 2000) and the estimated distance is $60 \mathrm{~cm}$. The delay time $t_{d}$ becomes

$$
t_{d}=\frac{0.60}{5180}=0.12 \mathrm{~ms}
$$

This delay is used for a speed dependent correction of the accelerometer sensor data in the following analysis. The assumption is that the delay time is constant in the time domain $t_{d}$ and varies in the crank angle domain $\theta_{d}$ according to the crank angle speed.

$$
\theta_{d}=t_{d} \frac{N_{r p m}}{60} 360 \quad[\mathrm{CAD}]
$$

The angular delays are listed in Table 4. Ponti et al. (2013) found the delay to be $0.4 \mathrm{~s}$ for a diesel engine of $1 / 10$ of the size as the engine used here, but it was then assumed that the only source of the vibration is the combustion pressure. That restriction is not used here.

\section{ESTIMATION OF BURN RATE PARAMETERS}

The accumulated signal energy is calculated as

$$
E\left(\theta_{n}\right)=\sum_{k=0}^{n} u_{w}^{2}\left(\theta_{k}\right)
$$




\begin{tabular}{|l|l|l|}
\hline $\begin{array}{l}\text { Engine speed } \\
(\mathrm{rpm})\end{array}$ & $\begin{array}{l}\text { time delay } \\
(\mathrm{ms})\end{array}$ & $\begin{array}{l}\text { angular delay } \\
\text { (CAD) }\end{array}$ \\
\hline 1200 & 0.12 & 0.9 \\
1500 & 0.12 & 1.1 \\
1800 & 0.12 & 1.3 \\
\hline
\end{tabular}

Table 4. Angular delay for sensor 5 in cylinder 6 combustion for different engine speeds
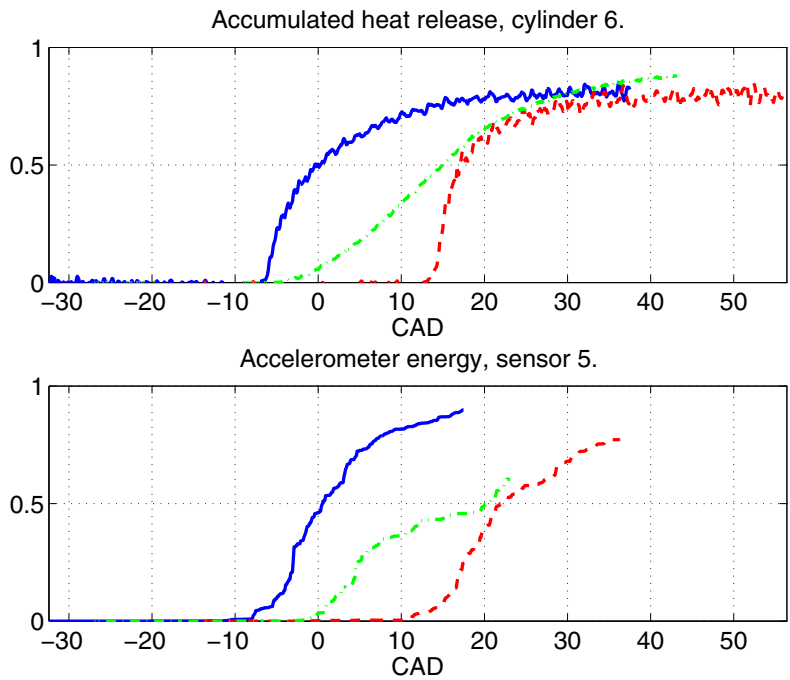

Fig. 5. Accumulated heat release and accelerometer energy for cylinder 6 and sensor 5 for three different injection timings.

This function is used to establish three measures, $\theta_{E 10}$, $\theta_{E 50}$ and $\theta_{E 90}$. They are calculated by interpolation in the energy function:

$$
\begin{aligned}
& \frac{E\left(\theta_{E 10}\right)}{E_{t o t}}=0.1 \\
& \frac{E\left(\theta_{E 50}\right)}{E_{t o t}}=0.5 \\
& \frac{E\left(\theta_{E 90}\right)}{E_{t o t}}=0.9
\end{aligned}
$$

The heat release is calculated from the cylinder pressure measurements using the Apparent Heat Release (AHR) method (Krieger and Borman, 1966):

$$
d Q_{h t}=\frac{\gamma}{\gamma-1} p d V+\frac{1}{\gamma-1} V d p
$$

The points in crank angle where $10 \%, 50 \%$ and $90 \%$ of the total accumulated heat release are reached, are referred to as $\theta_{Q 10}, \theta_{Q 50}$ and $\theta_{Q 90}$ further in this paper. Heat release analysis is difficult to get accurate. Brunt and Emtage (1997) showed that errors of \pm 2 CAD can easily appear for $\theta_{Q 10}-\theta_{Q 90}$ for small errors in absolute pressure referencing, compression ratio and angular reference.

Figure 5 shows an example of accumulated heat release and accelerometer energy for three different injection timings. It is notable that the starting point for both curves are very similar, but the shapes are different. This indicates that the method is likely to be more accurate to estimate the position of the early combustion rather than the position of the later part of the combustion.

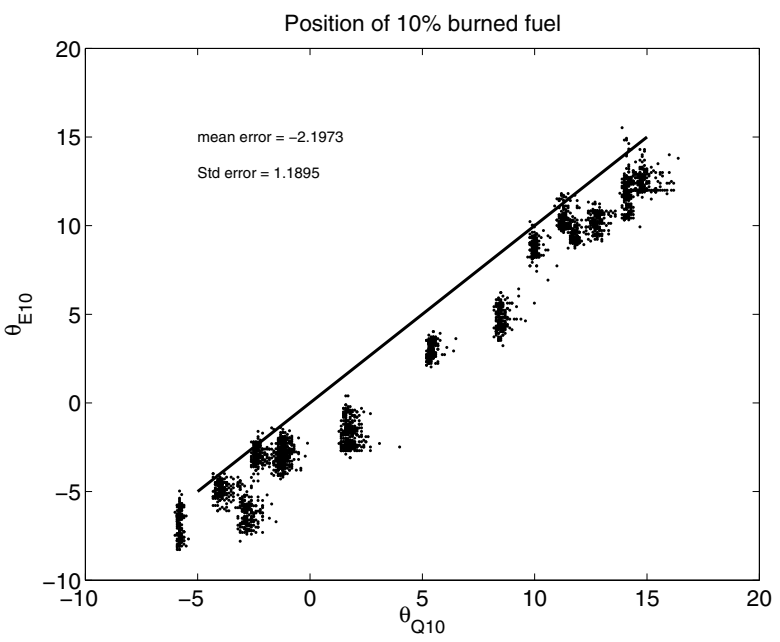

Fig. 6. $\theta_{E 10}$ compared to $\theta_{Q 10}$ cycle by cycle.

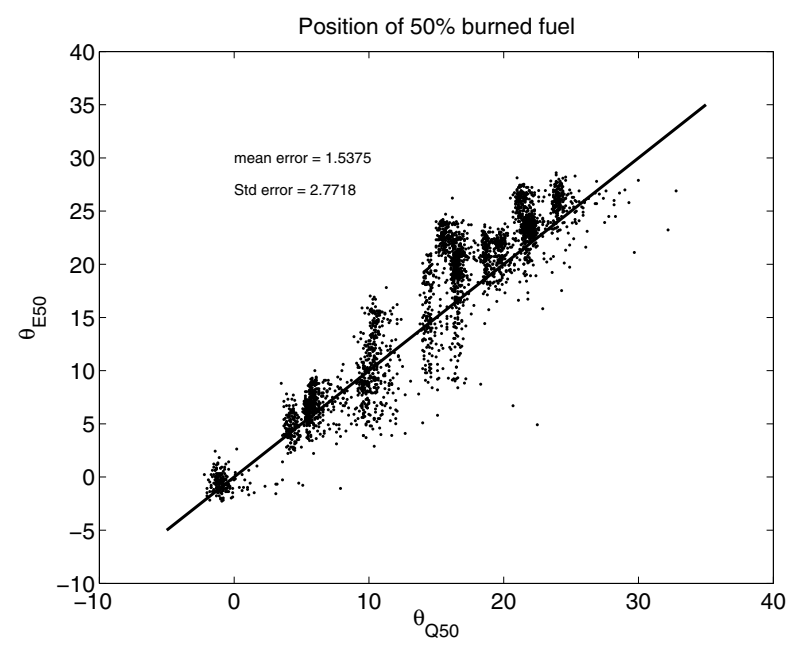

Fig. 7. $\theta_{E 50}$ compared to $\theta_{Q 50}$ cycle by cycle.

\section{RESULTS}

Figures 6 and 7 show the correlation between $\theta_{E 10}$ and $\theta_{Q 10}$, and $\theta_{E 50}$ and $\theta_{Q 50}$, for all data in the set. The important performance parameter is the standard deviation of the difference between the two, which is a measure of the precision of the method. The mean error is referred to as the accuracy of the method and can be addressed by several tools, e.g. linear regression or choosing a different ratio point for detection.

The results show that $\theta_{E 10}$ and $\theta_{E 50}$ can be used for estimating $\theta_{Q 10}$ and $\theta_{Q 50}$ with high accuracy and precisions of 1.5 CAD and $3 \mathrm{CAD}$, which is close to the precisions of $\theta_{Q 10}$ and $\theta_{Q 50}$ as discussed in Section 4. The $\theta_{Q 90}$ proved difficult to estimate with this energy method, which indicates that the energy approach to the accelerometer signal does not reveal all connections to the combustion process.

While the quality of the estimates looks high, the data will be further scrutinized for its validity. Figure 6 reveals that the $\theta_{E 10}$ always appears before the $\theta_{Q 10}$, and by such a distance that it is clear that the accelerometer reacts to other sources of vibration before the actual combustion 


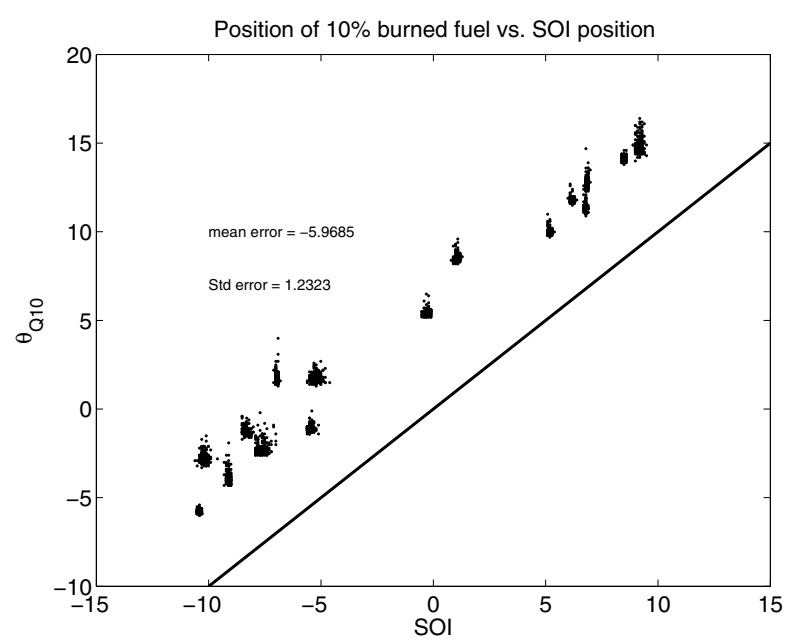

Fig. 8. $\theta_{Q 10}$ compared to the SOI position.

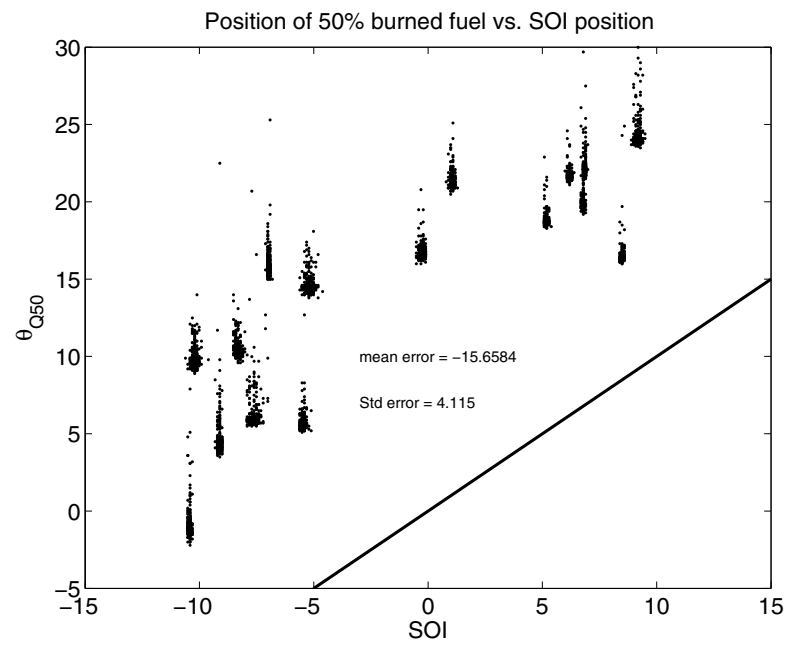

Fig. 9. $\theta_{Q 50}$ compared to the SOI position.

starts. Figure 8 shows the correlation between $\theta_{Q 10}$ and the SOI position, and it turns out that the the SOI position is as good at predicting the $\theta_{Q 10}$ as the accelerometer signal is. This is not the case for $\theta_{Q 50}$, where the SOI position is less informative than the accelerometer signal $\theta_{E 50}$, see Figures 7 and 9 .

The interpretation of this result is that the accelerometer signal is related to the start of injection as well as the combustion itself. One possible source of mechanical noise at SOI is when the injector needle hits its seat when opening, however, this could not be confirmed in this work.

\section{CONCLUSIONS}

The combustion events in a diesel engine have been monitored through engine block mounted accelerometer sensors. A method based on the signal energy from the accelerometers was developed and evaluated for this engine. It is demonstrated that the start of combustion (position of $10 \%$ heat released) and the combustion phasing (position of $50 \%$ heat released) can be estimated with a precision of 1.5 and $3 \mathrm{CAD}$ standard deviation respectively on a cycle to cycle basis. As indicators for these two positions, the $10 \%$ and $50 \%$ points of the accumulated accelerometer signal energy trace for each combustion are used.

The estimation precision is in the same range as the quality of the reference data. However, it can not be ruled out that a significant influence at $10 \%$ accelerometer energy comes from injector needle mechanical noise. This influence is less significant at the 50\% energy level.

The evaluation was done for a sensor position and firing cylinder that showed good signal to noise ratio between a combustion event and a motored event. The positioning of the sensor relative the measured cylinder is important. For the engine in this test it shows that a position far away from the cylinder of interest is better than a position close to it.

\section{ACKNOWLEDGMENTS}

This work was sponsored by Swedish Energy Agency (Svenska Energimyndigheten) within the research program FFI Strategic Vehicle Research and Innovation - Energy and Environment, and performed in cooperation with Volvo Powertrain, Vovlo Cars and Volvo Technology.

\section{ACRONYMS}

ATDC
CAD
NCV
SCV
SNR
SOC
SOI
TDC
$\theta_{Q 50}$
$\theta_{E 50}$

After top dead center

Crank angle degrees

Needle control valve

Spill control valve

Signal to noise ratio

Start of combustion

Start of injection

TDC Top dead center

$\theta_{Q 50} \quad$ Crank angle position when $50 \%$ of the total heat is released in one combustion Crank angle position when $50 \%$ of the accelerometer signal energy is accumulated

\section{REFERENCES}

Andersson, I., Thor, M., and McKelvey, T. (2012). The torque ratio concept for combustion monitoring of internal combustion engines. Control Engineering Practice, 20(6), 561-568.

Aono, T., Saruwatari, M., and Furuya, J. (2013). Estimation of engine torque and cylinder pressure index based on crankshaft rotation measurement. In Preprints of AAC 2013, Tokyo, Japan, 350-355. IFAC.

Brunt, M.F.J. and Emtage, A.L. (1997). Evaluation of burn rate routines and analysis errors. SAE Technical Paper Series $97003 \%$.

Chiavola, O., Chiatti, G., Arnone, L., and Manelli, S. (2010). Combustion characterization in diesel engine via block vibration analysis. SAE Technical paper 201001-0168.

Glavmo, M., Spadafora, P., and Bosch, R. (1999). Closed loop start of combustion control utilizing ionization sensing in a diesel engine. SAE Technical paper 199901-0549.

Krieger, R. and Borman, G. (1966). The computation of apparent heat release for internal combustion engines. $A S M E$ paper 66 - WA/DGP-4. 
Nordling, C. and Österman, J. (2000). Physics Handbook for Science and Engineering. Studentlitteratur, fifth edition. ISBN 91-44-16575-7.

Polonowski, C., Mathur, V., Naber, J., and Blough, J. (2007). Accelerometer based sensing of combusiotn in a high speed hpcr diesel engine. SAE Technical paper 200\%-01-0972.

Ponti, F., Ravaglioli, V., Corti, E., Moro, D., and De Cesare, M. (2013). Remote combustion sensing methodology for non-intrusive cylinder pressure estimation in diesel engines. In Preprints of AAC 2013, Tokyo, Japan, 343-349. IFAC.

Powell, D.J. (1993). Engine control using cylinder pressure: Past, present, and future. Journal of Dynamic Systems, Measurement, and Control, 115, 343-350.

Schnorbus, T., Pischinger, S., Koerfer, T., Lamping, M., Tomaszic, D., and Tatur, M. (2008). Diesel control with closed-loop control of the injection strategy. SAE paper 2008-01-0651.

Villarino, R. and Boehme, J. (2005). Pressure reconstruction and misfire detection from multichannel structureborne sound. SAE paper 2005-01-0040. 